\title{
Off-pump versus on-pump coronary artery bypass surgery in patients with actively treated diabetes and multivessel coronary disease
}

\author{
Umberto Benedetto, MD, PhD, Massimo Caputo, MD, Hunaid Vohra, PhD, Alan Davies, \\ James Hillier, MD, Alan Bryan, MD, and Gianni D. Angelini, MD
}

\section{ABSTRACT}

Objectives: We conducted a single-center analysis on short-term outcomes and long-term survival in actively treated diabetic patients undergoing off-pump coronary artery bypass versus on-pump coronary artery bypass surgery.

Methods: The final population consisted of 2450 patients with actively treated diabetes (mean age, $66 \pm 9$ years; female/male 545/1905, 22\%). Of those, 1493 subjects were orally treated and 1011 subjects were taking insulin. Offpump coronary artery bypass and on-pump coronary artery bypass were performed in 1253 and 1197 patients, respectively. Propensity score matching was used to compare the 2 matched groups.

Results: When compared with on-pump coronary artery bypass, off-pump coronary artery bypass was associated with a significant risk reduction for postoperative cerebrovascular accident (odds ratio, 0.49; 95\% confidence interval [CI], $0.25-0.99 ; P=.04$ ), need for postoperative intra-aortic balloon pump (odds ratio, $0.48 ; 95 \% \mathrm{CI}, 0.30-0.77 ; P=.002$ ), and reexploration for bleeding (odds ratio, $0.55 ; 95 \% \mathrm{CI}, 0.33-0.94 ; P=.02$ ). Off-pump coronary artery bypass did not significantly affect early (hazard ratio [HR], $1.32 ; 95 \% \mathrm{CI}, 0.73-2.40 ; P=.36$ ) and late (HR, 1.08; 95\% CI, 0.92-1.28; $P=.32$ ) mortality. However, off-pump coronary artery bypass with incomplete revascularization was associated with reduced survival when compared with off-pump coronary artery bypass with complete revascularization (HR, 1.82; 95\% CI, 1.34-2.46; $P=.0002$ ) and on-pump coronary artery bypass with complete revascularization (HR, 1.83 ; $95 \% \mathrm{CI}$, $1.36-2.47 ; P<.0001)$.

Conclusions: Off-pump coronary artery bypass is a safe and feasible option for diabetic patients with multivessel disease, reduces the incidence of early complications including postoperative cerebrovascular events, and provides excellent long-term survival similar to on-pump coronary artery bypass surgery in case of complete revascularization. (J Thorac Cardiovasc Surg 2016;152:1321-30)

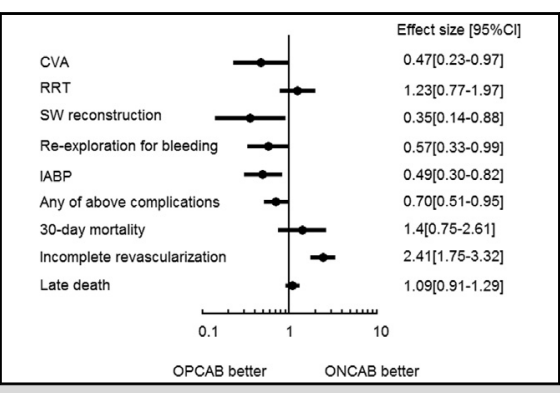

Effect of OPCAB grafting over ONCAB grafting on outcomes of interest.

\section{Central Message}

OPCAB surgery is a safe and feasible option for diabetic patients with multivessel disease, reduces the incidence of early complications, and provides long-term survival benefit similar to ONCAB surgery.

\section{Perspective}

OPCAB surgery remains a valid option for diabetic patients with multivessel disease because it reduces the incidence of early complications and provides long-term survival benefit similar to ONCAB. Its use should not be discouraged in such a high-risk subgroup.

See Editorial Commentary page 1331.
Diabetes mellitus (DM) is a major public health and economic problem with a dramatic increase in prevalence and incidence. ${ }^{1}$ Coronary heart disease is highly prevalent

From the Bristol Heart Institute, University of Bristol, School of Clinical Sciences, Bristol, United Kingdom.

This study was supported by the British Heart Foundation and the NIHR, Bristol Cardiovascular Biomedical Research Unit.

Received for publication Feb 19, 2016; revisions received May 23, 2016; accepted for publication June 17, 2016; available ahead of print Aug 2, 2016

Address for reprints: Umberto Benedetto, MD, PhD, Bristol Heart Institute, University of Bristol, Upper Maudlin St, Bristol BS2 8HW, United Kingdom (E-mail: umberto.benedetto@bristol.ac.uk).

$0022-5223 / \$ 36.00$

Crown Copyright (C) 2016 Published by Elsevier Inc. on behalf of The American Association for Thoracic Surgery

http://dx.doi.org/10.1016/j.jtcvs.2016.06.038 and the major cause of morbidity and mortality among diabetic patients. ${ }^{2}$ Patients with DM account for approximately one quarter of all patients who undergo coronary revascularization procedures each year. ${ }^{3}$ Coronary artery bypass grafting (CABG) when compared with percutaneous coronary intervention has been shown to be associated with better outcomes in patients with diabetes, ${ }^{4}$ and current clinical guidelines recommend $\mathrm{CABG}$ as the preferred

Scanning this QR code will take you to a video and supplemental figures and tables for the article.

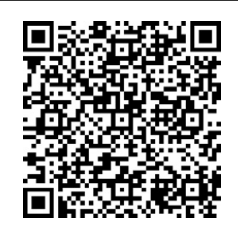




\section{Abbreviations and Acronyms \\ $\mathrm{CABG}=$ coronary artery bypass grafting \\ CI $=$ confidence interval \\ CVA $=$ cerebrovascular accident \\ $\mathrm{DM} \quad=$ diabetes mellitus \\ euroSCORE $=$ European System for Cardiac Operative Risk Evaluation \\ HR = hazard ratio \\ IR $=$ incomplete revascularization \\ IABP $=$ intra-aortic balloon pump \\ $\mathrm{ONCAB}=$ on-pump coronary artery bypass \\ $\mathrm{OPCAB}=$ off-pump coronary artery bypass \\ VIF $=$ variance inflation factor}

revascularization strategy in diabetic patients with complex coronary artery disease. ${ }^{5}$ However, DM has a significant negative impact on the clinical outcome of coronary surgery in the long term and short term. ${ }^{6}$ The debate on the effectiveness or otherwise of off-pump coronary artery bypass $(\mathrm{OPCAB})$ versus on-pump coronary artery bypass $(\mathrm{ON}-$ $\mathrm{CAB})$ surgery continues. ${ }^{7-9}$ In particular, the role of $\mathrm{OPCAB}$ in the management of diabetic patients remains controversial because comparative data are scarce and inconclusive. ${ }^{10-13} \mathrm{~A}$ recent subanalysis of the Bypass Angioplasty Revascularization Investigation 2 Diabetes trial $^{10}$ suggested that patients with diabetes had a greater risk of major cardiovascular long-term events after OPCAB than after ONCAB. However, this study presented several limitations, including a small sample size, and definitive conclusions could not be drawn. ${ }^{14}$ In this study, we used a large consecutive cohort with DM undergoing operation in a 20-year period at a single institution to perform a propensity score matching analysis of $\mathrm{ONCAB}$ versus $\mathrm{OPCAB}$ on short-term outcomes and long-term survival.

\section{MATERIALS AND METHODS}

The study was conducted in accordance with the principles of the Declaration of Helsinki. The local audit committee approved the study, and the requirement for individual patient consent was waived. We retrospectively analyzed prospectively collected data from the National Institute for Cardiovascular Outcomes Research National Adult Cardiac Surgery Audit registry for all isolated first-time CABG procedures performed at the Bristol Heart Institute (Bristol, UK) from April 1996 to April 2015. Reproducible cleaning algorithms were applied to the database, which are regularly updated as required. Briefly, duplicate records and nonadult cardiac surgery entries were removed, transcriptional discrepancies were harmonized, and clinical conflicts and extreme values were corrected or removed. The data are returned regularly to the local units for validation.

Further details and definition of variables are available at http://www. ucl.ac.uk/nicor/audits/adultcardiac/datasets. From 15,119 isolated firsttime $\mathrm{CABG}$ cases performed during the study period, we selected subjects with multivessel coronary artery disease and actively treated DM at the time of surgery. Patients with no diabetes $(n=12,439)$, single-vessel disease $(n=121)$, and no data regarding surgical strategy adopted (OPCAB vs $\mathrm{ONCAB}, \mathrm{n}=109$ ) were excluded. The final population consisted of 2450 patients (22\%; mean age, $66 \pm 9$ years; female/male 545/1905) with actively treated diabetes. Of those, 1493 patients were orally treated and 1011 patients were receiving insulin. OPCAB (Video 1) and ONCAB were performed in 1253 and 1197 patients, respectively (Figure 1) according to the surgeon's preference and not according to specific clinical indications. Normothermic blood cardioplegia was the standard strategy for ONCAB cases during the study period. Blood glucose level was strictly maintained at less than $11.1 \mathrm{mmol} / \mathrm{L}$ perioperatively according to unit protocol, using insulin infusion.

\section{Pretreatment Variables and Study End Points}

The effect of OPCAB over ONCAB was adjusted for the following variables: age, gender, body mass index, previous myocardial infarction within 30 days, previous percutaneous coronary intervention, diabetes mellitus (DM) on insulin, chronic obstructive pulmonary disease, Canadian Cardiovascular Society class III or IV, New York Heart Association class III or IV, current smoking, serum creatinine $200 \mathrm{mmol} / \mathrm{L}$ or greater, previous cerebrovascular accident (CVA), peripheral vascular disease, preoperative atrial fibrillation, left main disease, 3-vessel disease, left ventricle ejection fraction $49 \%$ or less and $30 \%$ or less, preoperative use of intra-aortic balloon pump (IABP), nonelective admission, emergency/salvage operation, cardiogenic shock, and year of operation. Overall risk profile was evaluated by using additive and logistic European System for Cardiac Operative Risk Evaluation (euroSCORE). Incomplete revascularization (IR) was defined as at least 1 diseased primary arterial territory not grafted.

Short-term outcomes investigated were postoperative complications, including CVA, need for IABP defined as unplanned insertion of IABP intraoperatively or postoperatively because of hemodynamic instability, reexploration for bleeding, renal replacement therapy, sternal wound reconstruction as single and combined end points, and mortality within 30 days. Long-term outcome was all-cause mortality. All-cause mortality is the most robust and unbiased index because no adjudication is required; thus, inaccurate or biased documentation or clinical assessments are avoided. ${ }^{15}$ Information about death was obtained from the institutional database and the National General Register Office for all patients. Data regarding postoperative complications and survival were available for all patients in the study.

\section{Statistical Analysis}

For baseline characteristics, variables are summarized as mean for continuous variables and proportion for categoric variables. Multiple imputation using bootstrapping-based expectation-maximization algorithm and including all pretreatment variables (Amelia $\mathrm{R}$ package, http://www. jstatsoft.org/v45/i07/) was used to address missing data (Table E1). To control for measured potential confounders in the data set, a propensity score was generated for each patient from a multivariable logistic regression model based on pretreatment covariates as independent variables with treatment type (OPCAB vs ONCAB) as a binary dependent variable. ${ }^{16}$ The resulting propensity score represented the probability of a patient to undergo OPCAB (area under the curve 0.63) (Figure E1). Pairs of patients receiving $\mathrm{OPCAB}$ and $\mathrm{ONCAB}$ were derived using greedy 1:1 matching with a caliper of width of 0.2 standard deviation of the logit of the propensity score (nonrandom $\mathrm{R}$ package, http://CRAN.Rproject.org/ package $=$ nonrandom). The quality of the match was assessed by comparing selected pretreatment variables in propensity score-matched patients using the standardized mean difference, by which an absolute standardized difference of greater than $10 \%$ is suggested to represent meaningful covariate imbalance. ${ }^{16}$ Analytic methods for the estimation of the treatment effect in the matched sample included McNemar's to compare proportions. ${ }^{16}$ Time-segmented Cox regression models (within 30 days and $>30$ days $)^{17}$ that stratified on the matched pairs ${ }^{18}$ were used to investigate the effect of treatment (ONCAB vs ONCAB) on early and late mortality. This approach accounts for the within-pair homogeneity by allowing the baseline hazard function to vary across matched sets (survival R package, http://CRAN.R-project.org/package=survival). Last, a multivariate 


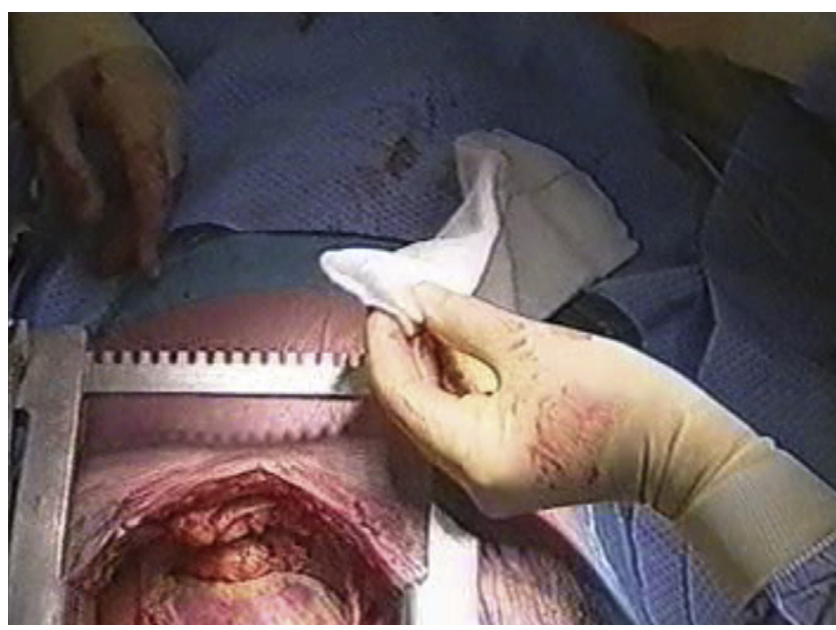

VIDEO 1. OPCAB grafting technique at Bristol Heart Institute. Video available at: http://www.jtcvsonline.org/article/S0022-5223(16)30668-7/addons.

adjustment for all baseline characteristics and intraoperative variables, such as the use of bilateral internal thoracic arteries, radial artery (RA), and the incidence of IR, was performed in the matched sample to correct the effect of OPCAB for residual imbalance (double robust) and to estimate the effect size of other covariates on all outcomes investigated. Pearson correlation coefficient and variance inflation factors (VIFs) from the covariance matrix of parameter estimates were used to assess collinearity in multivariate models (usdm $\mathrm{R}$ package, http://CRAN.R-project.org/ package $=u s d m$ ). Variables with VIF greater than 4 were excluded from multivariate analyses. All statistical analysis was performed using R Statistical Software (version 3.2.3; R Foundation for Statistical Computing, Vienna, Austria).

\section{RESULTS}

Distribution of pretreatment variables in the OPCAB and ONCAB groups is summarized in Table 1. Patients undergoing ONCAB were likely to have Canadian Cardiovascular Society III/IV, 3-vessel disease, left ventricle ejection fraction of $30 \%$ or less, and cardiogenic shock. The era of surgery also was different between the 2 groups. Additive euroSCORE $(P=.02)$, but not logistic euroSCORE $(P=.15)$, was higher in the ONCAB group. Propensity score matching created a total of 995 pairs perfectly matched for all pretreatment variables (standardized mean difference $<0.10$ ) including era of surgery. In the matched population, additive euroSCORE $(P=.08)$ and logistic euroSCORE $(P=.12)$ were comparable between the 2 groups.

\section{Intraoperative Data}

Table 2 summarizes intraoperative data. When compared with $\mathrm{ONCAB}, \mathrm{OPCAB}$ was associated with a lower number of grafts per patient $(2.7 \pm 0.7$ vs $3.0 \pm 0.7, P<.001)$ (Figure 2) in the right and circumflex arteries but not the left anterior descending artery territory. The rate of bilateral internal thoracic artery was low in both groups $(P=.1)$. The use of the radial artery was higher in the OPCAB group, and the saphenous vein graft was used more frequently in the ONCAB group. OPCAB conversion rate to ONCAB was 7 in $1253(0.6 \%)$.

\section{Effect of Off-Pump Coronary Artery Bypass on Short-Term Outcomes}

Short-term outcomes are summarized in Table 3. OPCAB was associated with a higher rate of IR. When compared with $\mathrm{ONCAB}, \mathrm{OPCAB}$ was significantly associated with $50 \%$ relative risk reduction for postoperative CVA $(P=.04)$, need for postoperative IABP $(P=.002)$, and reexploration for bleeding $(P=.02)$. Overall 30-day mortality

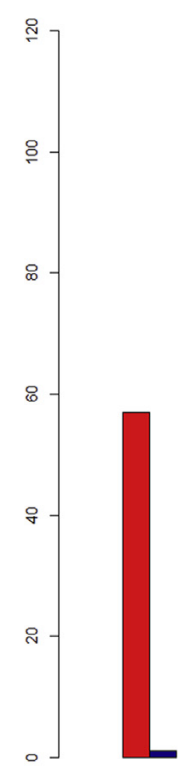

1996

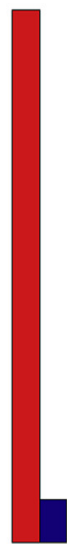

1997

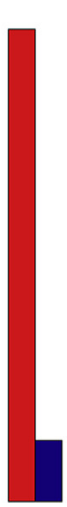

1998

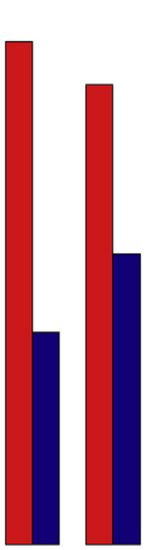

2000
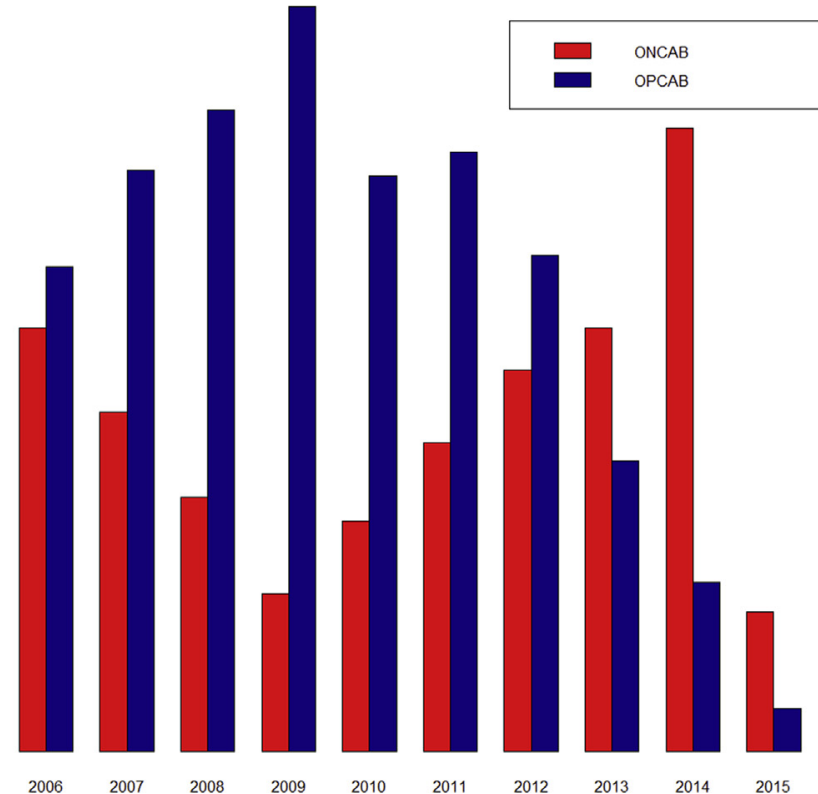

FIGURE 1. Number of OPCAB and ONCAB operations during the study period. $O N C A B$, On-pump coronary artery bypass; $O P C A B$, off-pump coronary artery bypass. 
TABLE 1. Pretreatment variables distribution in the unmatched and matched off-pump coronary artery bypass and on-pump coronary artery bypass groups

\begin{tabular}{|c|c|c|c|c|c|c|c|c|c|c|}
\hline & \multicolumn{2}{|c|}{ Unmatched OPCAB } & \multicolumn{2}{|c|}{ Unmatched OPCAB } & \multirow[b]{2}{*}{ SMD } & \multicolumn{2}{|c|}{ PS matched OPCAB } & \multicolumn{2}{|c|}{ PS matched OPCAB } & \multirow[b]{2}{*}{ SMD } \\
\hline & $\mathbf{n}$ & $\%$ & n & $\%$ & & $\mathbf{n}$ & $\%$ & n & $\%$ & \\
\hline Total sample & 1253 & 100.0 & 1197 & 100.0 & & 995 & 100.0 & 995 & 100.0 & \\
\hline \multicolumn{11}{|l|}{ Age, y } \\
\hline$<60.0$ & 307 & 24.5 & 282 & 23.6 & 4.8 & 242 & 24.3 & 233 & 23.4 & 2.4 \\
\hline $60-69$ & 449 & 35.8 & 490 & 40.9 & & 360 & 36.2 & 393 & 39.5 & \\
\hline $70-79$ & 440 & 35.1 & 401 & 33.5 & & 346 & 34.8 & 345 & 34.7 & \\
\hline$\geq 8$ & 57 & 4.5 & 24 & 2.0 & & 47 & 4.7 & 24 & 2.4 & \\
\hline \multicolumn{11}{|l|}{ Female } \\
\hline No & 976 & 77.9 & 929 & 77.6 & 0.7 & 765 & 76.9 & 762 & 76.6 & 0.7 \\
\hline Yes & 277 & 22.1 & 268 & 22.4 & & 230 & 23.1 & 233 & 23.4 & \\
\hline \multicolumn{11}{|l|}{ BMI } \\
\hline$<30$ & 723 & 57.7 & 726 & 60.7 & 7.5 & 575 & 57.8 & 575 & 57.8 & 1.1 \\
\hline$\geq 30$ & 530 & 42.3 & 471 & 39.3 & & 420 & 42.2 & 420 & 42.2 & \\
\hline \multicolumn{11}{|l|}{$\mathrm{CCS}$} \\
\hline No & 654 & 52.2 & 526 & 43.9 & 16.5 & 514 & 51.7 & 491 & 49.3 & 4.6 \\
\hline Yes & 599 & 47.8 & 671 & 56.1 & & 481 & 48.3 & 504 & 50.7 & \\
\hline \multicolumn{11}{|l|}{ NYHA } \\
\hline No & 791 & 63.1 & 704 & 58.8 & 8.8 & 624 & 62.7 & 611 & 61.4 & 2.7 \\
\hline Yes & 462 & 36.9 & 493 & 41.2 & & 371 & 37.3 & 384 & 38.6 & \\
\hline \multicolumn{11}{|c|}{ MI within $30 \mathrm{~d}$} \\
\hline No & 985 & 78.6 & 932 & 77.9 & 1.8 & 796 & 80.0 & 768 & 77.2 & 6.8 \\
\hline Yes & 268 & 21.4 & 265 & 22.1 & & 199 & 20.0 & 227 & 22.8 & \\
\hline \multicolumn{11}{|l|}{ PCI } \\
\hline No & 1157 & 92.3 & 1125 & 94.0 & 6.5 & 917 & 92.2 & 925 & 93.0 & 3.0 \\
\hline Yes & 96 & 7.7 & 72 & 6.0 & & 78 & 7.8 & 70 & 7.0 & \\
\hline \multicolumn{11}{|c|}{$\mathrm{DM}$ on insulin } \\
\hline No & 733 & 58.5 & 706 & 59.0 & 0.9 & 583 & 58.6 & 584 & 58.7 & 0.2 \\
\hline Yes & 520 & 41.5 & 491 & 41.0 & & 412 & 41.4 & 411 & 41.3 & \\
\hline \multicolumn{11}{|c|}{ Current smoking } \\
\hline No & 1117 & 89.1 & 1060 & 88.6 & 1.8 & 889 & 89.3 & 888 & 89.2 & 0.3 \\
\hline Yes & 136 & 10.9 & 137 & 11.4 & & 106 & 10.7 & 107 & 10.8 & \\
\hline \multicolumn{11}{|c|}{$\mathrm{sCr}>200 \mathrm{mmol} / \mathrm{L}$} \\
\hline No & 1204 & 96.1 & 1147 & 95.8 & 1.3 & 956 & 96.1 & 958 & 96.3 & 1.0 \\
\hline Yes & 49 & 3.9 & 50 & 4.2 & & 39 & 3.9 & 37 & 3.7 & \\
\hline \multicolumn{11}{|l|}{ COPD } \\
\hline No & 1140 & 91.0 & 1086 & 90.7 & 0.8 & 903 & 90.8 & 899 & 90.4 & 1.3 \\
\hline Yes & 113 & 9.0 & 111 & 9.3 & & 92 & 9.2 & 96 & 9.6 & \\
\hline CVA & & & & & & & & & & \\
\hline No & 1179 & 94.1 & 1131 & 94.5 & 1.6 & 931 & 93.6 & 940 & 94.5 & 3.8 \\
\hline Yes & 74 & 5.9 & 66 & 5.5 & & 64 & 6.4 & 55 & 5.5 & \\
\hline PVD & & & & & & & & & & \\
\hline No & 1075 & 85.8 & 991 & 82.8 & 8.2 & 853 & 85.7 & 848 & 85.2 & 1.4 \\
\hline Yes & 178 & 14.2 & 206 & 17.2 & & 142 & 14.3 & 147 & 14.8 & \\
\hline $\mathrm{AF}$ & & & & & & & & & & \\
\hline No & 1198 & 95.6 & 1142 & 95.4 & 0.9 & 949 & 95.4 & 951 & 95.6 & 0.9 \\
\hline Yes & 55 & 4.4 & 55 & 4.6 & & 46 & 4.6 & 44 & 4.4 & \\
\hline 3-vessel disea & & & & & & & & & & \\
\hline No & 346 & 27.6 & 230 & 19.2 & 19.9 & 298 & 29.9 & 224 & 22.5 & 9.2 \\
\hline Yes & 907 & 72.4 & 967 & 80.8 & & 697 & 70.1 & 771 & 77.5 & \\
\hline LMD & & & & & & & & & & \\
\hline No & 964 & 76.9 & 913 & 76.3 & 1.5 & 770 & 77.4 & 753 & 75.7 & 4.0 \\
\hline Yes & 289 & 23.1 & 284 & 23.7 & & 225 & 22.6 & 242 & 24.3 & \\
\hline
\end{tabular}


TABLE 1. Continued

\begin{tabular}{|c|c|c|c|c|c|c|c|c|c|c|}
\hline & \multicolumn{2}{|c|}{ Unmatched OPCAB } & \multicolumn{2}{|c|}{ Unmatched OPCAB } & \multirow[b]{2}{*}{ SMD } & \multicolumn{2}{|c|}{ PS matched OPCAB } & \multicolumn{2}{|c|}{ PS matched OPCAB } & \multirow[b]{2}{*}{ SMD } \\
\hline & $\mathbf{n}$ & $\%$ & $\mathbf{n}$ & $\%$ & & $\mathbf{n}$ & $\%$ & $\mathbf{n}$ & $\%$ & \\
\hline \multicolumn{11}{|l|}{ LVEF $<50 \%$} \\
\hline No & 839 & 67.0 & 786 & 65.7 & 2.7 & 660 & 66.3 & 663 & 66.6 & 0.6 \\
\hline Yes & 414 & 33.0 & 411 & 34.3 & & 335 & 33.7 & 332 & 33.4 & \\
\hline \multicolumn{11}{|l|}{ LVEF $30 \%-49 \%$} \\
\hline No & 923 & 73.7 & 902 & 75.4 & 2.7 & 729 & 73.3 & 737 & 74.1 & \\
\hline Yes & 330 & 26.3 & 295 & 24.6 & & 266 & 26.7 & 258 & 25.9 & \\
\hline \multicolumn{11}{|l|}{ LVEF $<30 \%$} \\
\hline No & 1169 & 93.3 & 1081 & 90.3 & 10.9 & 926 & 93.1 & 921 & 92.6 & 1.9 \\
\hline Yes & 84 & 6.7 & 116 & 9.7 & & 69 & 6.9 & 74 & 7.4 & \\
\hline \multicolumn{11}{|l|}{ Cardiogenic shock } \\
\hline No & 1247 & 99.5 & 1178 & 98.4 & 10.9 & 990 & 99.5 & 990 & 99.5 & 0.0 \\
\hline Yes & 6 & 0.5 & 19 & 1.6 & & 5 & 0.5 & 5 & 0.5 & \\
\hline \multicolumn{11}{|l|}{ Preoperative IABP } \\
\hline No & 1237 & 98.7 & 1167 & 97.5 & 9.0 & 981 & 98.6 & 981 & 98.6 & 0.3 \\
\hline Yes & 16 & 1.3 & 30 & 2.5 & & 14 & 1.4 & 14 & 1.4 & \\
\hline \multicolumn{11}{|l|}{ Nonelective } \\
\hline No & 644 & 51.4 & 560 & 46.8 & 9.2 & 520 & 52.3 & 476 & 47.8 & 8.8 \\
\hline Yes & 609 & 48.6 & 637 & 53.2 & & 475 & 47.7 & 519 & 52.2 & \\
\hline \multicolumn{11}{|l|}{ Emergency/salvage } \\
\hline No & 1239 & 98.9 & 1171 & 97.8 & 8.3 & 982 & 98.7 & 980 & 98.5 & 1.7 \\
\hline Yes & 14 & 1.1 & 26 & 2.2 & & 13 & 1.3 & 15 & 1.5 & \\
\hline \multicolumn{11}{|l|}{ Era of surgery } \\
\hline $1996-2004$ & 398 & 31.8 & 306 & 25.6 & 34.6 & 254 & 25.5 & 256 & 25.7 & 9.8 \\
\hline $2005-2007$ & 267 & 21.3 & 349 & 29.2 & & 273 & 27.4 & 276 & 27.7 & \\
\hline $2008-2010$ & 324 & 25.9 & 283 & 23.6 & & 240 & 24.1 & 269 & 27.0 & \\
\hline 2011-2015 & 264 & 21.1 & 259 & 21.6 & & 228 & 22.9 & 194 & 19.5 & \\
\hline Additive euroSCORE & $4.2 \pm 2.6$ & & $4.4 \pm 2.8$ & & & $4.2 \pm 2.7$ & & $4.2 \pm 2.5$ & & \\
\hline Logistic euroSCORE & $5 \% \pm 5 \%$ & & $5 \% \pm 7 \%$ & & & $5 \% \pm 5 \%$ & & $4 \% \pm 5 \%$ & & \\
\hline
\end{tabular}

OPCAB, Off-pump coronary artery bypass; $S M D$, standardized mean difference; $P S$, propensity score; $B M I$, body mass index; $C C S$, Canadian Cardiovascular Class; $N Y H A$, New York Heart Association; $M I$, myocardial infarction; $P C I$, percutaneous coronary intervention; $D M$, diabetes mellitus; $s C r$, serum creatinine; $C O P D$, chronic obstructive pulmonary disease; $C V A$, cerebrovascular accident; $P V D$, peripheral vascular disease; $A F$, atrial fibrillation; $L M D$, left main disease; $L V E F$, left ventricular ejection fraction; $I A B P$, intraaortic balloon pump; euroSCORE, European System for Cardiac Operative Risk Evaluation.

was $2.4 \%$ (58 patients) with no significant difference between the 2 groups. This trend toward a benefit from OP$\mathrm{CAB}$ on short-term outcomes was confirmed when the results were analyzed separately for patients receiving oral or insulin treatment (Tables E2 and E3). There were no deaths in the 7 patients undergoing OPCAB who required conversion to $\mathrm{ONCAB}$.

\section{Effect of Off-Pump Coronary Artery Bypass on Long-Term Mortality}

At a mean follow-up of $6.5 \pm 4.5$ years, there were 357 and 408 deaths in the unmatched population and 284 and 299 deaths in the matched sample in the OPCAB and ONCAB groups, respectively (Figure 2). In the matched sample, survival probability at 5 and 10 years was $82.6 \% \pm 1.2 \%$ and $62.6 \% \pm 2.0 \%$ versus $84.3 \% \pm$ $1.3 \%$ and $64.0 \% \pm 1.9 \%$ in the OPCAB and ONCAB groups, respectively. The 2 strategies were perfectly comparable in terms of late mortality in the overall matched sample (hazard ratio [HR], 1.08; 95\% confidence interval $[\mathrm{CI}], 0.92-1.28 ; P=.32)$ and among patients orally treated (HR, 1.06; 95\% CI, $0.85-1.33 ; P=.6)$ and receiving insulin (HR, 1.12; 95\% CI, 0.88-1.43) $(P=.35)$ (Figure 3)

OPCAB with complete revascularization showed comparable survival when compared with $\mathrm{ONCAB}$ with complete revascularization $(\mathrm{n}=921)(\mathrm{HR}, 1.00 ; 95 \% \mathrm{CI}, 0.84-1.20$; $P=.96)$. However, patients undergoing OPCAB with IR ( $\mathrm{n}=139)$ showed reduced survival when compared with OPCAB with complete revascularization $(\mathrm{n}=856)(\mathrm{HR}$, 1.82; 95\% CI, 1.34-2.46; $P=.0002)$ and ONCAB with complete revascularization (HR, 1.83 ; 95\% CI, 1.36-2.47; $P<.0001$ ) (Figure 4). We could not draw conclusions on the impact on IR among ONCAB cases because of the small sample size $(\mathrm{n}=74)$.

\section{Effect of Off-Pump Coronary Artery Bypass Versus On-Pump Coronary Artery Bypass After Full Adjustment (Double Robust)}

After double robust adjustment, OPCAB was confirmed to be significantly associated with a reduced incidence of 
TABLE 2. Intraoperative data

\begin{tabular}{|c|c|c|c|c|c|}
\hline & \multicolumn{2}{|c|}{ ОРСАВ } & \multicolumn{2}{|c|}{ ONCAB } & \multirow[b]{2}{*}{$P$ value } \\
\hline & $\mathbf{n}$ & $\%$ & $\mathbf{n}$ & $\%$ & \\
\hline Overall & 1253 & 100.0 & 1197 & 100.0 & \\
\hline \multicolumn{6}{|l|}{ No. of grafts } \\
\hline 1 & 36 & 2.9 & 6 & 0.5 & \multirow[t]{6}{*}{$<.001$} \\
\hline 2 & 447 & 35.7 & 253 & 21.1 & \\
\hline 3 & 650 & 51.9 & 703 & 58.7 & \\
\hline 4 & 119 & 9.5 & 222 & 18.5 & \\
\hline 5 & 1 & 0.1 & 12 & 1.0 & \\
\hline 6 & 0 & 0.0 & 1 & 0.1 & \\
\hline Mean No. of grafts/patient & $2.7 \pm 0.7$ & & $3.0 \pm 0.7$ & & \\
\hline \multicolumn{6}{|l|}{ Graft target } \\
\hline \multicolumn{6}{|l|}{ LAD } \\
\hline No & 35 & 2.8 & 33 & 2.8 & \multirow[t]{2}{*}{1} \\
\hline Yes & 1218 & 97.2 & 1164 & 97.2 & \\
\hline \multicolumn{6}{|l|}{ DIA } \\
\hline No & 1020 & 81.4 & 931 & 77.8 & \multirow[t]{2}{*}{.03} \\
\hline Yes & 233 & 18.6 & 266 & 22.2 & \\
\hline \multicolumn{6}{|l|}{ CX } \\
\hline No & 313 & 25.0 & 142 & 11.9 & \multirow[t]{2}{*}{$<.001$} \\
\hline Yes & 940 & 75.0 & 1055 & 88.1 & \\
\hline \multicolumn{6}{|l|}{$\mathrm{RCA}$} \\
\hline No & 398 & 31.8 & 305 & 25.5 & \multirow[t]{2}{*}{$<.001$} \\
\hline Yes & 855 & 68.2 & 892 & 74.5 & \\
\hline \multicolumn{6}{|l|}{ RITA } \\
\hline No & 1224 & 97.7 & 1160 & 96.9 & \multirow[t]{2}{*}{.3} \\
\hline Yes & 29 & 2.3 & 37 & 3.1 & \\
\hline \multicolumn{6}{|l|}{ LITA } \\
\hline No & 76 & 6.1 & 113 & 9.4 & \multirow[t]{2}{*}{.002} \\
\hline Yes & 1177 & 93.9 & 1084 & 90.6 & \\
\hline \multicolumn{6}{|l|}{ BITA } \\
\hline No & 1230 & 98.2 & 1163 & 97.2 & \multirow[t]{2}{*}{.1} \\
\hline Yes & 23 & 1.8 & 34 & 2.8 & \\
\hline \multicolumn{6}{|l|}{ RA } \\
\hline No & 986 & 78.7 & 1083 & 90.5 & \multirow[t]{2}{*}{$<.001$} \\
\hline Yes & 267 & 21.3 & 114 & 9.5 & \\
\hline \multicolumn{6}{|l|}{ SV } \\
\hline No & 137 & 10.9 & 58 & 4.8 & \multirow[t]{2}{*}{$<.001$} \\
\hline Yes & 1116 & 89.1 & 1139 & 95.2 & \\
\hline \multicolumn{6}{|l|}{ Sequential grafts } \\
\hline No & 1154 & 92.1 & 1150 & 96.1 & $<.001$ \\
\hline Yes & 99 & 7.9 & 47 & 3.9 & \\
\hline
\end{tabular}

$\overline{O P C A B}$, Off-pump coronary artery bypass; $O N C A B$, on-pump coronary artery bypass; $L A D$, left anterior descending artery; $D I A$, diagonal branch; $C X$, circumflex artery; $R C A$, right coronary artery; RITA, right interior thoracic artery; LITA, left interior thoracic artery; BITA, bilateral internal thoracic artery; $R A$, radial artery; $S V$, saphenous vein.

postoperative stroke, need for postoperative IABP, sternal wound reconstruction, and reexploration for bleeding, but not dialysis. OPACB was significantly associated with a 2-fold increased risk of IR. OPCAB was not associated with increased early (within 30 days) and late mortality (Table E4).

\section{Impact of Other Predictors of Outcomes}

The impact of other predictors on outcomes of interest is reported in Tables E5-E13. In particular, diabetic patients taking insulin were significantly associated with an increased risk of postoperative dialysis and incidence of any complication. Diabetic patients taking insulin did not significantly affect early mortality, but they were associated with an $18 \%$ relative risk increase in late mortality. IR did not significantly influence operative outcomes and early mortality, but it was associated with an approximately $50 \%$ relative risk increase in late mortality. All variables investigated showed VIF less than 4 (Table E14). 



FIGURE 2. Survival curves in the unmatched and matched OPCAB and ONCAB groups. $H R$, Hazard ratio; ONCAB, on-pump coronary artery bypass; $O P C A B$, off-pump coronary artery bypass; $P S$, propensity score.

TABLE 3. Short-term outcomes in the unmatched and matched off-pump coronary artery bypass and on-pump coronary artery bypass groups with relative effect size in the propensity score-matched population

\begin{tabular}{|c|c|c|c|c|c|c|c|c|c|c|}
\hline & \multicolumn{2}{|c|}{ Unmatched OPCAB } & \multicolumn{2}{|c|}{ Unmatched ONCAB } & \multicolumn{2}{|c|}{ PS matched OPCAB } & \multicolumn{2}{|c|}{ PS matched ONCAB } & \multirow{2}{*}{$\begin{array}{c}\text { PS matched/ } \\
\text { adjusted estimate } \\
(95 \% \mathrm{CI})\end{array}$} & \multirow{2}{*}{$\begin{array}{c}\text { Adjusted } \\
P \text { value }\end{array}$} \\
\hline & $\mathbf{n}$ & $\%$ & $\mathbf{n}$ & $\%$ & $\mathbf{n}$ & $\%$ & $\mathbf{n}$ & $\%$ & & \\
\hline Sample size & 1253 & 100.0 & 1197 & 100.0 & 995 & 100.0 & 995 & 100.0 & & \\
\hline \multicolumn{11}{|l|}{ CVA } \\
\hline No & 1235 & 98.6 & 1167 & 97.5 & 983 & 98.8 & 971 & 97.6 & $0.49(0.25-0.99)$ & .04 \\
\hline Yes & 18 & 1.4 & 30 & 2.5 & 12 & 1.2 & 24 & 2.4 & & \\
\hline \multicolumn{11}{|l|}{ RRT } \\
\hline No & 1193 & 95.2 & 1144 & 95.6 & 946 & 95.1 & 952 & 95.7 & $1.15(0.75-1.74)$ & .52 \\
\hline Yes & 60 & 4.8 & 53 & 4.4 & 49 & 4.9 & 43 & 4.3 & & \\
\hline \multicolumn{11}{|l|}{ IABP } \\
\hline No & 1221 & 97.4 & 1136 & 94.9 & 969 & 97.4 & 942 & 94.7 & $0.48(0.30-0.77)$ & .002 \\
\hline Yes & 32 & 2.6 & 61 & 5.1 & 26 & 2.6 & 53 & 5.3 & & \\
\hline \multicolumn{11}{|l|}{ SWR } \\
\hline No & 1240 & 99.0 & 1180 & 98.6 & 985 & 99.0 & 979 & 98.4 & $0.62(0.28-1.38)$ & .24 \\
\hline Yes & 13 & 1.0 & 17 & 1.4 & 10 & 1.0 & 16 & 1.6 & & \\
\hline \multicolumn{11}{|l|}{ Reexploration } \\
\hline No & 1224 & 97.7 & 1155 & 96.5 & 973 & 97.8 & 956 & 96.1 & $0.55(0.33-0.94)$ & .02 \\
\hline Yes & 29 & 2.3 & 42 & 3.5 & 22 & 2.2 & 39 & 3.9 & & \\
\hline \multicolumn{11}{|c|}{ Any complication } \\
\hline No & 1118 & 89.2 & 1028 & 85.9 & 890 & 89.4 & 849 & 85.3 & $0.69(0.52-0.90)$ & .005 \\
\hline Yes & 135 & 10.8 & 169 & 14.1 & 105 & 10.6 & 146 & 14.7 & & \\
\hline \multicolumn{11}{|l|}{ 30-d mortality } \\
\hline No & 1221 & 97.4 & 1171 & 97.8 & 970 & 97.5 & 976 & 98.1 & $1.32(0.73-2.40)$ & .36 \\
\hline Yes & 32 & 2.6 & 26 & 2.2 & 25 & 2.5 & 19 & 1.9 & & \\
\hline \multicolumn{11}{|l|}{ IR } \\
\hline No & 1062 & 84.8 & 1102 & 92.1 & 865 & 86.9 & 921 & 92.6 & $2(1.50-2.7)$ & $<.001$ \\
\hline Yes & 191 & 15.2 & 95 & 7.9 & 139 & 14.0 & 74 & 7.4 & & \\
\hline
\end{tabular}


PS-matched orally treated diabetics

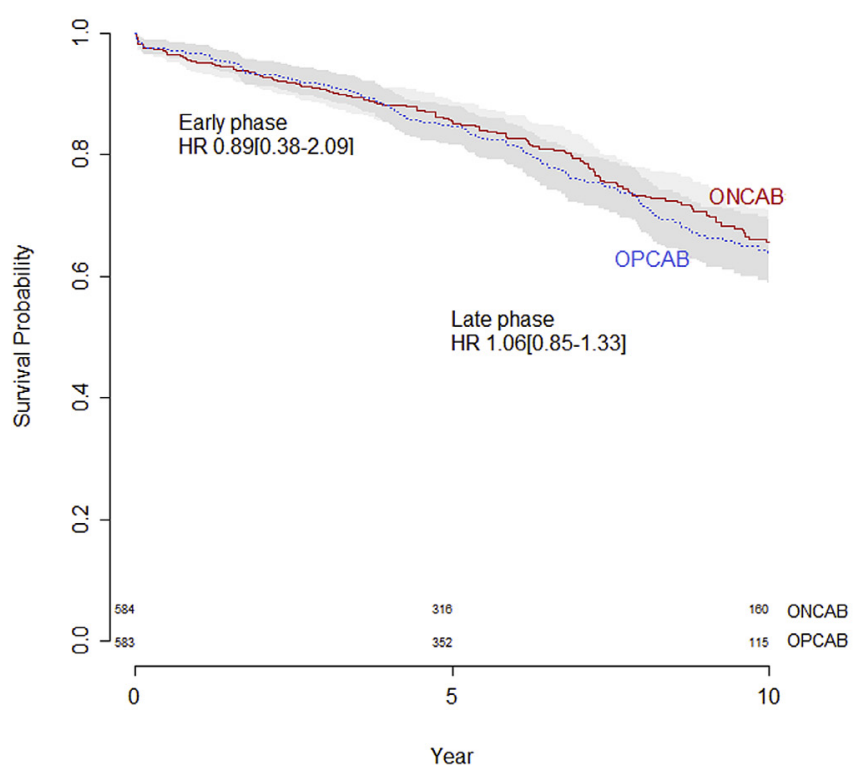

PS-matched diabetics on insulin



FIGURE 3. Survival curves in the matched OPCAB and ONCAB groups in patients receiving oral treatment and in patients receiving insulin. $H R$, Hazard ratio; $O N C A B$, on-pump coronary artery bypass; $O P C A B$, off-pump coronary artery bypass; $P S$, propensity score.

\section{DISCUSSION}

To the best of our knowledge, this is the largest series with the longest follow-up reported on the impact of OPCAB in diabetic patients with multivessel coronary disease. OPCAB was associated with a trend toward a lower incidence of postoperative complications, including cardiovascular accidents, and comparable early and late survivals when compared with ONCAB. The present analysis confirmed that OPCAB was associated with an approximately $7 \%$ absolute risk increase in IR. Furthermore, OPCAB with IR showed a lower survival when compared with OPCAB and $\mathrm{ONCAB}$ with complete revascularization. Insulin treatment was confirmed to be an independent risk factor for postoperative complications and poorer long-term survival.

Despite several randomized controlled trials, there is still controversy with respect to the advantages and disadvantages of OPCAB versus OPCAB surgery. ${ }^{7-9,19,20}$ However, some evidence has suggested a potential off-pump benefit for patient subgroups with a high operative risk. ${ }^{21-23}$ In the case of diabetic patients with multivessel disease, limited data are available with conflicting reports. ${ }^{10-13}$ A recent observational subanalysis of the Bypass Angioplasty Revascularization Investigation 2 Diabetes trial ${ }^{10}$ concluded that patients with diabetes had a greater risk of major long-term cardiovascular events after OPCAB than after ONCAB. However, this study has been criticized $^{14}$ because of the small number of patients compared (153 propensity-matched pairs), which is inadequate to draw final conclusions. Moreover, there was missing information regarding the completeness of revascularization. A subanalysis of the Randomized On/Off Bypass trial ${ }^{11}$ on diabetic patients randomized to OPCAB $(\mathrm{n}=402)$ or ONCAB $(n=433)$ concluded that 1-year graft patency rate was lower after $\mathrm{OPCAB}$ with no difference in the 1-year primary composite outcome. However, it is largely recognized that in the Randomized On/Off Bypass trial, surgeons were inexperienced (on average performing 8 $\mathrm{OPCAB}$ operations per year and with a high conversion rate of $\sim 12 \%) .{ }^{14}$ The importance of surgeon experience in OPCAB is clearly demonstrated in trials that showed no difference in hard clinical end points at 1 year or longer follow-up. ${ }^{7,8,24}$ Moreover, the $1 \%$ lower graft patency rate reported in the OPCAB group is clearly marginal $(83.1 \%$ vs $88.4 \%$ ), and it is likely not to have any clinical impact. On the other hand, Emmert and colleagues ${ }^{12}$ compared short-term outcomes in 540 diabetic patients undergoing $\mathrm{OPCAB}$ and 475 diabetic patients undergoing ONCAB and showed a clear trend to reduced major complications, such as stroke, rethoracotomy for bleeding, and postoperative IABP requirement, confirming the beneficial effect of OPCAB on short-term outcomes in this subset of patients. Renner and colleagues ${ }^{13}$ compared 355 OPCAB and 502 ONCAB procedures and concluded that OPCAB was associated with a significantly lower 30-day mortality risk and a lower 1-year mortality risk compared with ONCAB.

In the present analysis, IR occurred in $15.2 \%$ and $7.9 \%$ of unmatched OPCAB and ONCAB groups, respectively. Although patients undergoing OPCAB with complete revascularization showed survival similar to those receiving ONCAB, OPCAB with IR was found to be significantly associated with a lower survival when compared with OP$\mathrm{CAB}$ and $\mathrm{ONCAB}$ with complete revascularization. It has 


\section{OPCAB vs ONCAB according to completeness of revascularization}

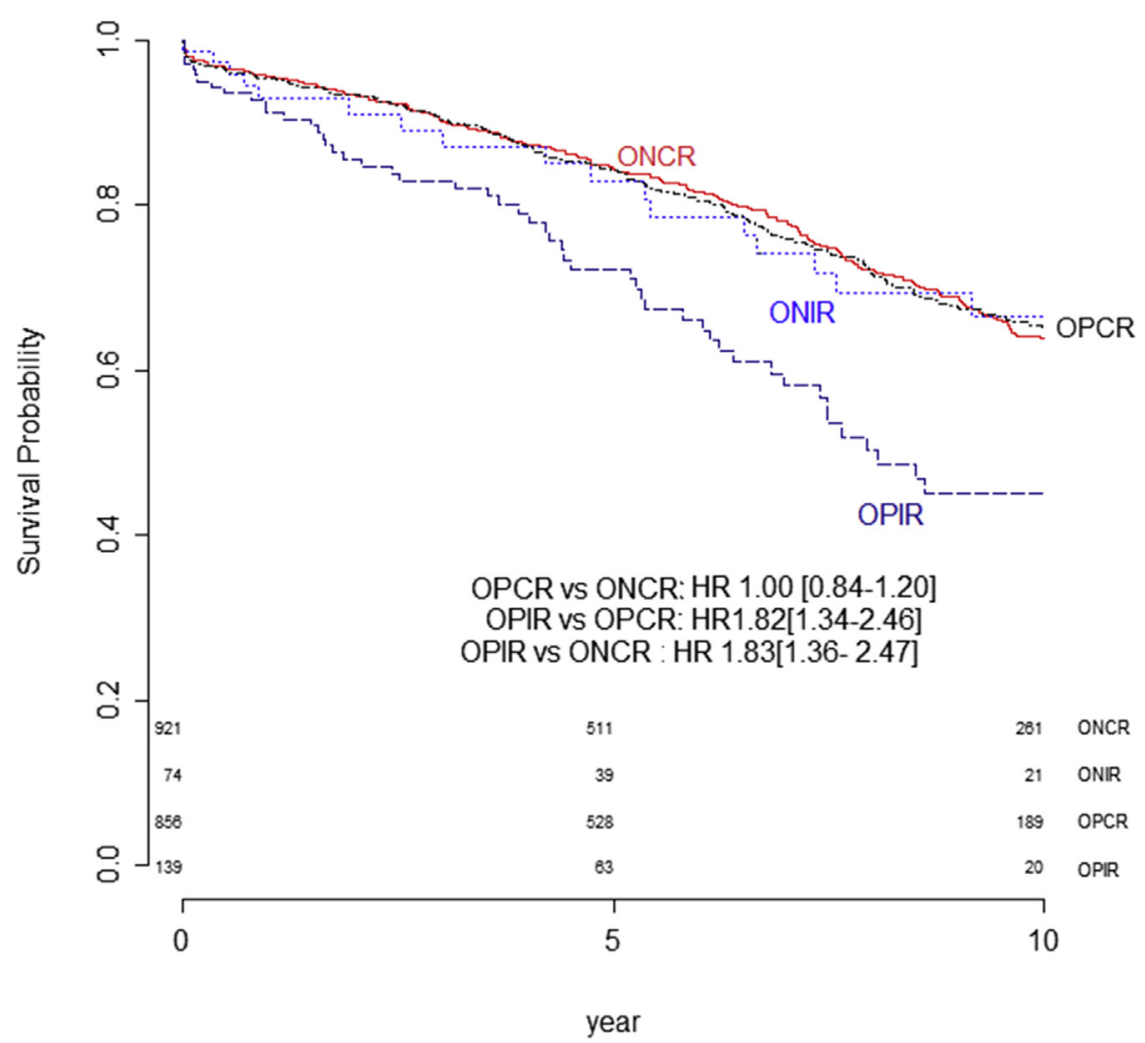

FIGURE 4. Survival curves in the matched OPCAB and ONCAB groups in patients with complete revascularization and IR. $O P C A B$, Off-pump coronary artery bypass; $O N C A B$, on-pump coronary artery bypass; $O N C R$, on pump-complete revascularization; $O N I R$, on-pump incomplete revascularization; $O P C R$, off-pump complete revascularization; $O P I R$, off-pump incomplete revascularization; $H R$, hazard ratio.

been suggested that patients who undergo IR have multiple comorbidities and unfavorable anatomy that could bias the data in favor of complete revascularization. ${ }^{25}$ However, compelling evidence supports the hypothesis that diabetic patients are more likely to benefit from a more complete revascularization. $^{26}$ Raza and colleagues ${ }^{27}$ recently reported a long-term survival analysis on 11,922 diabetic patients and demonstrated that complete revascularization was associated with $10 \%$ lower late mortality. Moreover, they found that OPCAB was associated with a $10 \%$ lower late mortality than ONCAB, but the difference was not statistically significant $(P=.2)$. Nakano and colleagues ${ }^{28}$ reported on 604 consecutive patients who underwent OPCAB during a 6-year period with 216 patients receiving IR $(13 \%)$. They found that all the event-free survivals for all-cause mortality $(P<.001)$, cardiac death $(P=.020)$, and major adverse cardiac and cerebrovascular events $(P<.001)$ were lower in the IR group. Of note, the IR rate observed in the present OPCAB series was significantly lower than that reported by others. Omer and colleagues ${ }^{29}$ recently reported a $29 \%$ rate of IR in 6367 OPCAB cases compared with $11.0 \%$ in 34,772 ONCAB cases. Kleisli and colleagues ${ }^{30}$ reported a $22 \%$ rate of IR in 207 OPCAB cases and $6.3 \%$ in 827 ONCAB cases. Some have suggested that surgeon experience plays a role and emphasized the importance of surgeon volume in establishing favorable outcomes for OPCAB. ${ }^{24}$ The relatively low rate of IR in the present OPCAB series is likely to be related to the high OPCAB volume in our center and supports the hypothesis that when OPCAB is routinely performed, complete revascularization can be achieved in the majority of cases. The trend toward shorter survival with OPCAB observed in some studies may be related to $\operatorname{IR}^{27,28}$ more likely to occur in cases with surgeons who are less experienced with this technique. Finally, although the use of additional arterial grafts has been shown to minimize the risk related to $\mathrm{IR},{ }^{31}$ the rate of bilateral internal thoracic arteries usage was low $(\sim 2 \%)$ in the present series. This may represent the concern of increased sternal wound complication in this high-risk group of patients. ${ }^{27}$

\section{Study Limitations}

The main limitation of our study is that no follow-up data were available to compare the groups with respect to the cause of death (cardiac vs noncardiac), recurrence of angina, need for repeated revascularization, and graft patency. Therefore, we can only speculate about the mechanism beyond the equipoise between $\mathrm{OPCAB}$ and $\mathrm{ONCAB}$ 
on long-term survival. Finally, although the data were collected prospectively, the nonspecific design for the diabetic population limits the present analysis. Propensity technique can adjust only for measurable and included variables but cannot exclude a selection bias based on nonmeasurable "eyeball."

\section{CONCLUSIONS}

OPCAB is a safe and feasible option for diabetic patients with multivessel coronary disease. OPCAB reduces the incidence of postoperative complications and provides long-term survival comparable to ONCAB. Complete revascularization should still be the main goal while performing $\mathrm{OPCAB}$ surgery in diabetic patients.

\section{Conflict of Interest Statement}

Authors have nothing to disclose with regard to commercial support.

\section{References}

1. Narayan KMV, Gregg EW, Fagot-Campagna A, Engelgau MM, Vinicor F. Diabetes: a common, growing, serious, costly, and potentially preventable public health problem. Diabetes Res Clin Pract. 2000;50(Suppl):77-84.

2. Berry C, Tardif JC, Bourassa MG. Coronary heart disease in patients with diabetes. Part I: recent advances in prevention and noninvasive management. J Am Coll Cardiol. 2007;49:631-42.

3. Berry C, Tardif JC, Bourassa MG. Coronary heart disease in patients with diabetes. Part II: recent advances in coronary revascularization. J Am Coll Cardiol. 2007; 49:643-56.

4. Farkouh ME, Domanski M, Sleeper LA, Siami FS, Dangas G, Mack M, et al. Strategies for multivessel revascularization in patients with diabetes. $N$ Engl J Med. 2012;367:2375-84

5. Kolh P, Windecker S, Alfonso F, Collet J-P, Cremer J, Falk V, et al. 2014 ESC/ EACTS Guidelines on myocardial revascularization: The Task Force on Myocardial Revascularization of the European Society of Cardiology (ESC) and the European Association for Cardio-Thoracic Surgery (EACTS). Eur J Cardiothorac Surg. 2014;46:517-92.

6. Kappetein AP, Head SJ, Morice MC, Banning AP, Serruys PW, Mohr FW, et al. Treatment of complex coronary artery disease in patients with diabetes: 5-year results comparing outcomes of bypass surgery and percutaneous coronary intervention in the SYNTAX trial. Eur J Cardiothorac Surg. 2013;43:1006-13.

7. Lamy A, Devereaux PJ, Prabhakaran D, Taggart DP, Hu S, Paolasso E, et al. Effects of off-pump and on-pump coronary-artery bypass grafting at 1 year. $N$ Engl J Med. 2013;368:1179-88.

8. Diegeler A, Börgermann J, Kappert U, Breuer M, Böning A, Ursulescu A, et al. Off-pump versus on-pump coronary-artery bypass grafting in elderly patients. N Engl J Med. 2013;368:1189-98.

9. Hattler B, Messenger JC, Shroyer AL, Collins JF, Haugen SJ, Garcia JA, et al. Off-pump coronary artery bypass surgery is associated with worse arterial and saphenous vein graft patency and less effective revascularization: results from the Veterans Affairs Randomized On/Off Bypass (ROOBY) trial. Circulation. 2012; 125:2827-35.

10. Singh A, Schaff HV, Mori Brooks M, Hlatky MA, Wisniewski SR, Frye RL, et al; BARI 2D Study Group. On-pump versus off-pump coronary artery bypass graft surgery among patients with type 2 diabetes in the Bypass Angioplasty Revascularization Investigation 2 Diabetes trial. Eur J Cardiothorac Surg. 2016;49: 406-16.

11. Shroyer AL, Hattler B, Wagner TH, Baltz JH, Collins JF, Carr BM, et al; VA \#517 Randomized On/Off Bypass (ROOBY) Study Group. Comparing off-pump and on-pump clinical outcomes and costs for diabetic cardiac surgery patients. Ann Thorac Surg. 2014;98:38-44.
12. Emmert MY, Salzberg SP, Seifert B, Rodriguez H, Plass A, Hoerstrup SP, et al. Is off-pump superior to conventional coronary artery bypass grafting in diabetic patients with multivessel disease? Eur J Cardiothorac Surg. 2011;40:233-9.

13. Renner A, Zittermann A, Aboud A, Pühler T, Hakim-Meibodi K, Quester W, et al. Coronary revascularization in diabetic patients: off-pump versus onpump surgery. Ann Thorac Surg. 2013;96:528-34.

14. Taggart DP. Off-pump coronary artery bypass graft in patients with type 2 diabetes: pushing the Bypass Angioplasty Revascularization Investigation Type 2 Diabetes trial too far. Eur J Cardiothorac Surg. 2016;49:416-8.

15. Lauer MS, Blackstone EH, Young JB, Topol EJ. Cause of death in clinical research: time for a reassessment? J Am Coll Cardiol. 1999;34:618-20.

16. Austin PC. A tutorial and case study in propensity score analysis: an application to estimate the effect of in-hospital smoking cessation counseling on mortality. Multivariate Behav Res. 2011;46:119-51.

17. Myers WO, Blackstone EH, Davis K, Foster ED, Kaiser GC. CASS Registry long term surgical survival. Coronary Artery Surgery Study. J Am Coll Cardiol. 1999; 33:488-98

18. Cummings P, McKnight B, Greenland S. Matched cohort methods for injury research. Epidemiol Rev. 2003;25:43-50.

19. Angelini GD, Taylor FC, Reeves BC, Ascione R. Early and midterm outcome after off-pump and on-pump surgery in Beating Heart Against Cardioplegic Arrest Studies (BHACAS 1 and 2): a pooled analysis of two randomised controlled trials. Lancet. 2002;359:1194-9.

20. Ascione R, Reeves BC, Taylor FC, Seehra HK, Angelini GD. Beating heart against cardioplegic arrest studies (BHACAS 1 and 2): quality of life at midterm follow-up in two randomised controlled trials. Eur Heart J. 2004;25:765-70.

21. Cavallaro P, Itagaki S, Seigerman M, Chikwe J. Operative mortality and stroke after on-pump vs off-pump surgery in high-risk patients: an analysis of 83,914 coronary bypass operations. Eur J Cardiothorac Surg. 2014;45:159-64.

22. Marui A, Okabayashi H, Komiya T, Tanaka S, Furukawa Y, Kita T, et al; CREDO-Kyoto Investigators. Benefits of off-pump coronary artery bypass grafting in high-risk patients. Circulation. 2012;126(11 Suppl 1):S151-7.

23. Ascione R, Reeves BC, Rees K, Angelini GD. Effectiveness of coronary artery bypass grafting with or without cardiopulmonary bypass in overweight patients. Circulation. 2002;106:1764-70.

24. Lapar DJ, Mery CM, Kozower BD, Kern JA, Kron IL, Stukenborg GJ, et al. The effect of surgeon volume on mortality for off-pump coronary artery bypass grafting. J Thorac Cardiovasc Surg. 2012;143:854-63.

25. Gossl M, Faxon DP, Bell MR, Holmes DR, Gersh BJ. Complete versus incomplete revascularization with coronary artery bypass graft or percutaneous intervention in stable coronary artery disease. Circ Cardiovasc Interv. 2012;5: 597-604.

26. Takagi H, Watanabe T, Mizuno Y, Kawai N, Umemoto T, ALICE (All-Literature Investigation of Cardiovascular Evidence) Group. A meta-analysis of adjusted risk estimates for survival from observational studies of complete versus incomplete revascularization in patients with multivessel disease undergoing coronary artery bypass grafting. Interact Cardiovasc Thorac Surg. 2014;18:679-82.

27. Raza S, Sabik JF III, Masabni K, Ainkaran P, Lytle BW, Blackstone EH. Surgical revascularization techniques that minimize surgical risk and maximize late survival after coronary artery bypass grafting in patients with diabetes mellitus. J Thorac Cardiovasc Surg. 2014;148:1257-64.

28. Nakano J, Okabayashi H, Noma H, Sato T, Sakata R. The impact of incomplete revascularization and angiographic patency on midterm results after off-pump coronary artery bypass grafting. J Thorac Cardiovasc Surg. 2014;147:1225-32.

29. Omer S, Cornwell LD, Rosengart TK, Kelly RF, Ward HB, Holman WL, et al. Completeness of coronary revascularization and survival: Impact of age and off-pump surgery. J Thorac Cardiovasc Surg. 2014;148:1307-15.

30. Kleisli T, Cheng W, Jacobs MJ, Mirocha J, Derobertis MA, Kass RM, et al. In the current era, complete revascularization improves survival after coronary artery bypass surgery. J Thorac Cardiovasc Surg. 2005;129:1283-9.

31. Kieser TM, Curran HJ, Rose MS, Norris CM, Graham MM. Arterial grafts balance survival between incomplete and complete revascularization: a series of 1000 consecutive coronary artery bypass graft patients with $98 \%$ arterial grafts. J Thorac Cardiovasc Surg. 2014;147:75-83.

Key Words: off-pump coronary artery bypass grafting, diabetes mellitus, survival 
TABLE E1. Percentage of missing data

\begin{tabular}{lcll}
\hline Preoperative IABP & 19.776 & COPD & 0.635 \\
sCr & 19.518 & CCS & 0.622 \\
BMI & 10.424 & AF & 0.622 \\
LMD & 7.494 & DM & 0.615 \\
MI 30 d & 7.322 & PCI & 0.463 \\
3-vessel disease & 1.984 & Shock & 0.417 \\
CVA & 1.508 & Nonelective & 0.093 \\
LVEF & 1.27 & Emergency/salvage & 0.093 \\
Current smoking & 0.701 & Age & 0 \\
NYHA & 0.688 & Female & 0 \\
PVD & 0.661 & Era of surgery & 0 \\
\hline
\end{tabular}

$I A B P$, Intra-aortic balloon pump; $C O P D$, chronic obstructive pulmonary disease; $s C r$, serum creatinine; $C C S$, Canadian Cardiovascular Class; $B M I$, body mass index; $A F$, atrial fibrillation; $L M D$, left main disease; $D M$, diabetes mellitus; $M I$, myocardial infarction; $P C I$, percutaneous coronary intervention; $C V A$, cerebrovascular accident; $L V E F$, left ventricular ejection fraction; NYHA, New York Heart Association; PVD, peripheral vascular disease.

TABLE E2. Short-term outcomes in patients with orally treated diabetes in the unmatched and matched off-pump coronary artery bypass and onpump coronary artery bypass groups with relative effect size in the propensity score-matched population

\begin{tabular}{|c|c|c|c|c|c|c|c|c|c|c|}
\hline & \multicolumn{2}{|c|}{ Unmatched OPCAB } & \multicolumn{2}{|c|}{ Unmatched ONCAB } & \multicolumn{2}{|c|}{ PS matched OPCAB } & \multicolumn{2}{|c|}{ PS matched ONCAB } & \multirow{2}{*}{$\begin{array}{c}\text { Adjusted estimate } \\
(95 \% \text { CI })\end{array}$} & \multirow{2}{*}{$\begin{array}{c}\text { Adjusted } \\
P \text { value }\end{array}$} \\
\hline & $\mathbf{n}$ & $\%$ & $\mathbf{n}$ & $\%$ & $\mathbf{n}$ & $\%$ & $\mathbf{n}$ & $\%$ & & \\
\hline Sample size & 733 & 100.0 & 706 & 100.0 & 583 & 100.0 & 584 & 100.0 & & \\
\hline \multicolumn{11}{|l|}{ CVA } \\
\hline No & 724 & 98.8 & 685 & 97.0 & 578 & 99.1 & 568 & 97.3 & $0.31(0.11-0.84)$ & .02 \\
\hline Yes & 9 & 1.2 & 21 & 3.0 & 5 & 0.9 & 16 & 2.7 & & \\
\hline \multicolumn{11}{|l|}{ RRT } \\
\hline No & 706 & 96.3 & 683 & 96.7 & 562 & 96.4 & 565 & 96.7 & $1.11(0.59-2.09)$ & .74 \\
\hline Yes & 27 & 3.7 & 23 & 3.3 & 21 & 3.6 & 19 & 3.3 & & \\
\hline \multicolumn{11}{|l|}{$\mathrm{IABP}$} \\
\hline No & 714 & 97.4 & 672 & 95.2 & 569 & 97.6 & 555 & 95.0 & $0.47(0.25-0.90)$ & .02 \\
\hline Yes & 19 & 2.6 & 34 & 4.8 & 14 & 2.4 & 29 & 5.0 & & \\
\hline \multicolumn{11}{|l|}{ SWR } \\
\hline No & 728 & 99.3 & 696 & 98.6 & 579 & 99.3 & 575 & 98.5 & $0.44(0.14-1.44)$ & .17 \\
\hline Yes & 5 & 0.7 & 10 & 1.4 & 4 & 0.7 & 9 & 1.5 & & \\
\hline \multicolumn{11}{|l|}{ Reexploration } \\
\hline No & 717 & 97.8 & 681 & 96.5 & 570 & 97.8 & 560 & 95.9 & $0.53(0.27-1.05)$ & .07 \\
\hline Yes & 16 & 2.2 & 25 & 3.5 & 13 & 2.2 & 24 & 4.1 & & \\
\hline \multicolumn{11}{|c|}{ Any complication } \\
\hline No & 663 & 90.5 & 614 & 87.0 & 531 & 91.1 & 505 & 86.5 & $0.63(0.43-0.90)$ & .01 \\
\hline Yes & 70 & 9.5 & 92 & 13.0 & 52 & 8.9 & 79 & 13.5 & & \\
\hline \multicolumn{11}{|l|}{ 30-d mortality } \\
\hline No & 717 & 97.8 & 691 & 97.9 & 573 & 98.3 & 573 & 98.1 & $0.89(0.38-2.09)$ & .78 \\
\hline Yes & 16 & 2.2 & 15 & 2.1 & 10 & 1.7 & 11 & 1.9 & & \\
\hline \multicolumn{11}{|l|}{ IR } \\
\hline No & 621 & 84.7 & 653 & 92.5 & 499 & 85.6 & 543 & 93.0 & $2.2(1.51-3.3)$ & $<.001$ \\
\hline Yes & 112 & 15.3 & 53 & 7.5 & 84 & 14.4 & 41 & 7.0 & & \\
\hline
\end{tabular}


TABLE E3. Short-term outcomes in patients receiving insulin in the unmatched and matched off-pump coronary artery bypass and on-pump coronary artery bypass groups with relative effect size in the propensity score-matched population

\begin{tabular}{|c|c|c|c|c|c|c|c|c|c|c|}
\hline & \multicolumn{2}{|c|}{ Unmatched OPCAB } & \multicolumn{2}{|c|}{ Unmatched ONCAB } & \multicolumn{2}{|c|}{ PS matched OPCAB } & \multicolumn{2}{|c|}{ PS matched ONCAB } & \multirow{2}{*}{$\begin{array}{c}\text { Adjusted estimate } \\
(95 \% \text { CI })\end{array}$} & \multirow{2}{*}{$\begin{array}{c}\text { Adjusted } \\
P \text { value } \\
\end{array}$} \\
\hline & $\mathbf{n}$ & $\%$ & $\mathbf{n}$ & $\%$ & $\mathbf{n}$ & $\%$ & $\mathbf{n}$ & $\%$ & & \\
\hline Sample size & 520 & 100.0 & 491 & 100 & 412 & 100.0 & 411 & 100.0 & & \\
\hline \multicolumn{11}{|l|}{ CVA } \\
\hline No & 511 & 98.3 & 482 & 98 & 405 & 98.3 & 403 & 98.1 & $0.87(0.31-2.42)$ & .79 \\
\hline Yes & 9 & 1.7 & 9 & 2 & 7 & 1.7 & 8 & 1.9 & & \\
\hline \multicolumn{11}{|l|}{ RRT } \\
\hline No & 487 & 93.7 & 461 & 94 & 384 & 93.2 & 387 & 94.2 & $1.18(0.67-2.06)$ & .57 \\
\hline Yes & 33 & 6.3 & 30 & 6 & 28 & 6.8 & 24 & 5.8 & & \\
\hline \multicolumn{11}{|l|}{ IABP } \\
\hline No & 507 & 97.5 & 464 & 95 & 400 & 97.1 & 387 & 94.2 & $0.48(0.24-0.98)$ & .04 \\
\hline Yes & 13 & 2.5 & 27 & 5 & 12 & 2.9 & 24 & 5.8 & & \\
\hline \multicolumn{11}{|l|}{ SWR } \\
\hline No & 512 & 98.5 & 484 & 99 & 406 & 98.5 & 404 & 98.3 & $0.85(0.28-2.56)$ & .77 \\
\hline Yes & 8 & 1.5 & 7 & 1 & 6 & 1.5 & 7 & 1.7 & & \\
\hline \multicolumn{11}{|c|}{ Reexploration } \\
\hline No & 507 & 97.5 & 474 & 97 & 403 & 97.8 & 396 & 96.4 & $0.59(0.26-1.36)$ & .21 \\
\hline Yes & 13 & 2.5 & 17 & 3 & 9 & 2.2 & 15 & 3.6 & & \\
\hline \multicolumn{11}{|c|}{ Any complication } \\
\hline No & 455 & 87.5 & 414 & 84 & 359 & 87.1 & 344 & 83.7 & $0.77(0.54-0.99)$ & .04 \\
\hline Yes & 65 & 12.5 & 77 & 16 & 53 & 12.9 & 67 & 16.3 & & \\
\hline \multicolumn{11}{|c|}{ 30-d mortality } \\
\hline No & 504 & 96.9 & 480 & 98 & 397 & 96.4 & 403 & 98.1 & $1.81(0.77-4.28)$ & .19 \\
\hline Yes & 16 & 3.1 & 11 & 2 & 15 & 3.6 & 8 & 1.9 & & \\
\hline \multicolumn{11}{|l|}{ IR } \\
\hline No & 441 & 84.8 & 449 & 91 & 357 & 86.7 & 378 & 92.0 & $1.76(1.12-2.8)$ & .01 \\
\hline Yes & 79 & 15.2 & 42 & 9 & 55 & 13.3 & 33 & 8.0 & & \\
\hline
\end{tabular}

TABLE E4. Effect of off-pump coronary artery bypass grafting over on-pump coronary artery bypass grafting on outcomes of interest in a fully adjusted double robust analysis

\begin{tabular}{|c|c|c|c|c|}
\hline & Effect size & Lower $95 \%$ CI & Upper $95 \%$ CI & $P$ value \\
\hline Postoperative CVA & $0.47 *$ & 0.23 & 0.97 & .04 \\
\hline Postoperative RRT & $1.23 *$ & 0.77 & 1.97 & .55 \\
\hline Sternal wound reconstruction & $0.35^{*}$ & 0.14 & 0.88 & .04 \\
\hline Reexploration for bleeding & $0.57 *$ & 0.33 & 0.99 & .04 \\
\hline Postoperative IABP & $0.49 *$ & 0.3 & 0.82 & .009 \\
\hline Any of above complications & $0.7 *$ & 0.51 & 0.95 & .02 \\
\hline Mortality at $30 \mathrm{~d}$ & $1.4 \dagger$ & 0.75 & 2.61 & .19 \\
\hline IR & $2.41 *$ & 1.75 & 3.32 & $<.0001$ \\
\hline Late mortality & $1.09 \dagger$ & 0.91 & 1.29 & .55 \\
\hline
\end{tabular}


TABLE E5. Double robust analysis on postoperative cerebrovascular accident

\begin{tabular}{|c|c|c|c|}
\hline & Effect & Lower $95 \%$ CI & Upper $95 \%$ CI \\
\hline OPCAB & 0.47 & 0.23 & 0.97 \\
\hline Age & 1.25 & 0.71 & 2.18 \\
\hline Female & 1.17 & 0.51 & 2.67 \\
\hline BMI & 1.43 & 0.82 & 2.51 \\
\hline Canadian Cardiovascular Class & 0.7 & 0.32 & 1.5 \\
\hline NYHA class & 1.29 & 0.59 & 2.8 \\
\hline MI within $30 \mathrm{~d}$ & 0.81 & 0.33 & 1.97 \\
\hline PCI & 1.26 & 0.39 & 4.01 \\
\hline DM on insulin & 1.03 & 0.5 & 2.11 \\
\hline Current smoking & 1.44 & 0.5 & 4.16 \\
\hline Creatinine $>200 \mathrm{mmol} / \mathrm{L}$ & 2.3 & 0.62 & 8.48 \\
\hline COPD & 0.33 & 0.07 & 1.52 \\
\hline Cerebrovascular accident & 4.16 & 1.67 & 10.36 \\
\hline Peripheral vascular disease & 2.1 & 0.94 & 4.68 \\
\hline Atrial fibrillation & 0.65 & 0.08 & 5.02 \\
\hline 3-vessel disease & 1.37 & 0.57 & 3.32 \\
\hline Left main disease & 1.61 & 0.75 & 3.43 \\
\hline Left ventricular ejection fraction $30 \%-49 \%$ & 0.62 & 0.27 & 1.46 \\
\hline Left ventricular ejection fraction $<30 \%$ & 0.49 & 0.1 & 2.53 \\
\hline Cardiogenic shock & 4.5 & 0.26 & 76.93 \\
\hline Preoperative IABP & 2.75 & 0.47 & 16.09 \\
\hline Nonelective & 1.57 & 0.71 & 3.49 \\
\hline Emergency/salvage & 2.76 & 0.4 & 18.91 \\
\hline Era of surgery & 1.81 & 1 & 3.28 \\
\hline Bilateral internal thoracic arteries & 2.21 & 0.26 & 18.59 \\
\hline Radial artery & 0.8 & 0.23 & 2.83 \\
\hline IR & 1.01 & 0.33 & 3.06 \\
\hline
\end{tabular}

CI, Confidence interval; OPCAB, off-pump coronary artery bypass; BMI, body mass index; NYHA, New York Heart Association; $M I$, myocardial infarction; $P C I$, percutaneous coronary intervention; $D M$, diabetes mellitus; $C O P D$, chronic obstructive pulmonary disease; IABP, intra-aortic balloon pump; IR, incomplete revascularization. 
TABLE E6. Double robust analysis on postoperative renal replacement therapy

\begin{tabular}{|c|c|c|c|}
\hline & Effect & Lower $95 \%$ CI & Upper $95 \%$ CI \\
\hline OPCAB & 1.23 & 0.77 & 1.97 \\
\hline Age & 1.22 & 0.86 & 1.74 \\
\hline Female & 0.76 & 0.43 & 1.34 \\
\hline BMI & 1.27 & 0.92 & 1.74 \\
\hline Canadian Cardiovascular Class & 1.25 & 0.78 & 2.01 \\
\hline NYHA Class & 0.73 & 0.45 & 1.21 \\
\hline MI within $30 \mathrm{~d}$ & 0.66 & 0.36 & 1.2 \\
\hline PCI & 0.74 & 0.32 & 1.72 \\
\hline DM on insulin & 1.91 & 1.22 & 3 \\
\hline Current smoking & 0.98 & 0.45 & 2.11 \\
\hline Creatinine $>200 \mathrm{mmol} / \mathrm{L}$ & 5.24 & 2.65 & 10.35 \\
\hline COPD & 0.66 & 0.31 & 1.41 \\
\hline Cerebrovascular accident & 2.11 & 1.04 & 4.27 \\
\hline Peripheral vascular disease & 1.47 & 0.85 & 2.53 \\
\hline Atrial fibrillation & 1.92 & 0.82 & 4.49 \\
\hline 3-vessel disease & 0.89 & 0.53 & 1.48 \\
\hline Left main disease & 1.44 & 0.88 & 2.37 \\
\hline Left ventricular ejection fraction $30 \%-49 \%$ & 0.94 & 0.56 & 1.57 \\
\hline Left ventricular ejection fraction $<30 \%$ & 1.26 & 0.56 & 2.86 \\
\hline Cardiogenic shock & 4.26 & 0.57 & 31.57 \\
\hline Preoperative IABP & 3.68 & 1.08 & 12.56 \\
\hline Nonelective & 1.05 & 0.64 & 1.72 \\
\hline Emergency/salvage & 1.16 & 0.18 & 7.38 \\
\hline Era of surgery & 1.95 & 1.29 & 2.94 \\
\hline Bilateral internal thoracic arteries & 0.94 & 0.12 & 7.34 \\
\hline Radial artery & 0.76 & 0.36 & 1.61 \\
\hline IR & 0.75 & 0.35 & 1.59 \\
\hline
\end{tabular}

$C I$, Confidence interval; $O P C A B$, off-pump coronary artery bypass; $B M I$, body mass index; $N Y H A$, New York Heart Association; $M I$, myocardial infarction; $P C I$, percutaneous coronary intervention; $D M$, diabetes mellitus; $C O P D$, chronic obstructive pulmonary disease; $I A B P$, intra-aortic balloon pump; $I R$, incomplete revascularization. 
TABLE E7. Double robust analysis on need for intra-aortic balloon pump

\begin{tabular}{|c|c|c|c|}
\hline & Effect & Lower $95 \%$ CI & Upper $95 \%$ CI \\
\hline OPCAB & 0.49 & 0.3 & 0.82 \\
\hline Age & 0.97 & 0.65 & 1.43 \\
\hline Female & 1.27 & 0.72 & 2.24 \\
\hline BMI & 0.82 & 0.6 & 1.11 \\
\hline Canadian Cardiovascular Class & 1.22 & 0.7 & 2.12 \\
\hline NYHA class & 1.29 & 0.74 & 2.25 \\
\hline MI within $30 \mathrm{~d}$ & 1.68 & 0.91 & 3.1 \\
\hline PCI & 0.78 & 0.31 & 1.97 \\
\hline DM on insulin & 1.18 & 0.71 & 1.96 \\
\hline Current smoking & 0.24 & 0.07 & 0.84 \\
\hline Creatinine $>200 \mathrm{mmol} / \mathrm{L}$ & 2.5 & 1.03 & 6.09 \\
\hline COPD & 0.65 & 0.26 & 1.66 \\
\hline Cerebrovascular accident & 0.3 & 0.04 & 2.24 \\
\hline Peripheral vascular disease & 0.77 & 0.38 & 1.55 \\
\hline Atrial fibrillation & 1.74 & 0.65 & 4.66 \\
\hline 3-vessel disease & 0.91 & 0.5 & 1.65 \\
\hline Left main disease & 1.31 & 0.75 & 2.29 \\
\hline Left ventricular ejection fraction $30 \%-49 \%$ & 2.09 & 1.17 & 3.76 \\
\hline Left ventricular ejection fraction $<30 \%$ & 8.3 & 4.32 & 15.93 \\
\hline Cardiogenic shock & 1.44 & 0.15 & 13.66 \\
\hline Preoperative IABP & 0.14 & 0.01 & 2.4 \\
\hline Nonelective & 0.87 & 0.48 & 1.57 \\
\hline Emergency/salvage & 6.34 & 2.08 & 19.29 \\
\hline Era of surgery & 1.75 & 1.15 & 2.66 \\
\hline Bilateral internal thoracic arteries & 3.58 & 0.89 & 14.33 \\
\hline Radial artery & 0.36 & 0.11 & 1.2 \\
\hline IR & 0.92 & 0.42 & 2.03 \\
\hline
\end{tabular}

CI, Confidence interval; $O P C A B$, off-pump coronary artery bypass; $B M I$, body mass index; NYHA, New York Heart Association; $M I$, myocardial infarction; $P C I$, percutaneous coronary intervention; $D M$, diabetes mellitus; $C O P D$, chronic obstructive pulmonary disease; $I A B P$, intra-aortic balloon pump; $I R$, incomplete revascularization. 
TABLE E8. Double robust analysis on risk of sternal wound reconstruction

\begin{tabular}{|c|c|c|c|}
\hline & Effect & Lower $95 \%$ CI & Upper $95 \%$ CI \\
\hline OPCAB & 0.35 & 0.14 & 0.88 \\
\hline Age & 2.52 & 1.19 & 5.34 \\
\hline Female & 0.52 & 0.15 & 1.84 \\
\hline BMI & 2.23 & 0.97 & 5.11 \\
\hline Canadian Cardiovascular Class & 1.07 & 0.44 & 2.59 \\
\hline NYHA class & 0.39 & 0.15 & 1.04 \\
\hline MI within $30 \mathrm{~d}$ & 0.43 & 0.13 & 1.43 \\
\hline PCI & 2.06 & 0.67 & 6.33 \\
\hline DM on insulin & 1.53 & 0.65 & 3.6 \\
\hline Current smoking & 0.81 & 0.16 & 3.97 \\
\hline Creatinine $>200 \mathrm{mmol} / \mathrm{L}$ & 4.56 & 1.26 & 16.52 \\
\hline COPD & 3.62 & 1.4 & 9.39 \\
\hline Cerebrovascular accident & 0.68 & 0.08 & 5.56 \\
\hline Peripheral vascular disease & 0.61 & 0.17 & 2.18 \\
\hline Atrial fibrillation & 1.25 & 0.27 & 5.8 \\
\hline 3-vessel disease & 0.33 & 0.13 & 1.01 \\
\hline Left main disease & 1.12 & 0.44 & 2.87 \\
\hline Left ventricular ejection fraction $30 \%-49 \%$ & 2.08 & 0.84 & 5.13 \\
\hline Left ventricular ejection fraction $<30 \%$ & 2.95 & 0.75 & 11.67 \\
\hline Cardiogenic shock & - & - & - \\
\hline Preoperative IABP & - & - & - \\
\hline Nonelective & 1.3 & 0.51 & 3.34 \\
\hline Emergency/salvage & - & - & - \\
\hline Era of surgery & 2 & 0.7 & 5.72 \\
\hline Bilateral internal thoracic arteries & - & - & - \\
\hline Radial artery & 2.07 & 0.62 & 6.93 \\
\hline IR & 1.01 & 0.21 & 4.92 \\
\hline
\end{tabular}

$C I$, Confidence interval; $O P C A B$, off-pump coronary artery bypass; $B M I$, body mass index; $N Y H A$, New York Heart Association; $M I$, myocardial infarction; $P C I$, percutaneous coronary intervention; $D M$, diabetes mellitus; $C O P D$, chronic obstructive pulmonary disease; $I A B P$, intra-aortic balloon pump; $I R$, incomplete revascularization. 
TABLE E9. Double robust analysis on risk of reexploration for bleeding

\begin{tabular}{|c|c|c|c|}
\hline & Effect & Lower $95 \%$ CI & Upper $95 \%$ CI \\
\hline OPCAB & 0.57 & 0.33 & 0.99 \\
\hline Age & 0.98 & 0.64 & 1.5 \\
\hline Female & 1.1 & 0.59 & 2.06 \\
\hline BMI & 0.91 & 0.64 & 1.31 \\
\hline Canadian Cardiovascular Class & 1.35 & 0.74 & 2.44 \\
\hline NYHA class & 0.55 & 0.29 & 1.03 \\
\hline MI within $30 \mathrm{~d}$ & 1.37 & 0.71 & 2.65 \\
\hline PCI & 0.33 & 0.08 & 1.44 \\
\hline DM on insulin & 0.93 & 0.53 & 1.64 \\
\hline Current smoking & 0.68 & 0.25 & 1.84 \\
\hline Creatinine $>200 \mathrm{mmol} / \mathrm{L}$ & 2.77 & 1.03 & 7.47 \\
\hline COPD & 1.39 & 0.59 & 3.29 \\
\hline Cerebrovascular accident & 0.54 & 0.13 & 2.3 \\
\hline Peripheral vascular disease & 0.72 & 0.32 & 1.65 \\
\hline Atrial fibrillation & 2.18 & 0.8 & 5.94 \\
\hline 3-vessel disease & 1.11 & 0.58 & 2.13 \\
\hline Left main disease & 0.7 & 0.37 & 1.33 \\
\hline Left ventricular ejection fraction $30 \%-49 \%$ & 0.72 & 0.37 & 1.4 \\
\hline Left ventricular ejection fraction $<30 \%$ & 1.66 & 0.71 & 3.9 \\
\hline Cardiogenic shock & 13.13 & 1.66 & 104.09 \\
\hline Preoperative IABP & - & - & - \\
\hline Nonelective & 2.54 & 1.31 & 4.93 \\
\hline Emergency/salvage & 4.85 & 1.21 & 19.39 \\
\hline Era of surgery & 1.08 & 0.67 & 1.75 \\
\hline Bilateral internal thoracic arteries & 1.81 & 0.37 & 8.83 \\
\hline Radial artery & 0.36 & 0.11 & 1.2 \\
\hline IR & 0.85 & 0.33 & 2.14 \\
\hline
\end{tabular}

$C I$, Confidence interval; $O P C A B$, off-pump coronary artery bypass; $B M I$, body mass index; $N Y H A$, New York Heart Association; $M I$, myocardial infarction; $P C I$, percutaneous coronary intervention; $D M$, diabetes mellitus; $C O P D$, chronic obstructive pulmonary disease; $I A B P$, intra-aortic balloon pump; $I R$, incomplete revascularization. 
TABLE E10. Double robust analysis on incidence of any complication among cerebrovascular accident, renal replacement therapy, need for intraaortic balloon pump, sternal wound reconstruction, and reexploration for bleeding

\begin{tabular}{|c|c|c|c|}
\hline & Effect & Lower $95 \%$ CI & Upper $95 \%$ CI \\
\hline OPCAB & 0.7 & 0.51 & 0.95 \\
\hline Age & 1.03 & 1.01 & 1.05 \\
\hline Female & 0.82 & 0.56 & 1.20 \\
\hline BMI & 1.03 & 1 & 1.06 \\
\hline Diabetes mellitus on insulin & 1.43 & 1.05 & 1.96 \\
\hline Canadian Cardiovascular Class & 1.08 & 0.77 & 1.50 \\
\hline NYHA class & 0.84 & 0.6 & 1.19 \\
\hline MI within $30 \mathrm{~d}$ & 1.06 & 0.72 & 1.54 \\
\hline PCI & 1.11 & 0.64 & 1.85 \\
\hline Current smoking & 0.77 & 0.42 & 1.31 \\
\hline Creatinine $>200 \mathrm{mmol} / \mathrm{L}$ & 5.15 & 2.98 & 8.75 \\
\hline COPD & 0.85 & 0.5 & 1.38 \\
\hline Cerebrovascular accident & 1.65 & 0.92 & 2.81 \\
\hline Peripheral vascular disease & 1.11 & 0.73 & 1.64 \\
\hline Atrial fibrillation & 1.27 & 0.63 & 2.34 \\
\hline 3-vessel disease & 0.75 & 0.52 & 1.08 \\
\hline Left main disease & 1.47 & 1.05 & 2.06 \\
\hline Left ventricular ejection fraction $30 \%-49 \%$ & 1.3 & 0.91 & 1.83 \\
\hline Left ventricular ejection fraction $<30 \%$ & 3.04 & 1.85 & 4.90 \\
\hline Cardiogenic shock & 0.85 & 0.13 & 4.38 \\
\hline Preoperative IABP & 1.43 & 0.44 & 3.88 \\
\hline Nonelective & 1.07 & 0.75 & 1.52 \\
\hline Emergency/salvage & 4.72 & 1.8 & 11.81 \\
\hline Era of surgery & 1.65 & 1.14 & 2.41 \\
\hline Bilateral internal thoracic arteries & 1.27 & 0.72 & 2.37 \\
\hline Radial artery & 0.71 & 0.41 & 1.18 \\
\hline IR & 1.05 & 0.62 & 1.71 \\
\hline
\end{tabular}

CI, Confidence interval; $O P C A B$, off-pump coronary artery bypass; $B M I$, body mass index; NYHA, New York Heart Association; $M I$, myocardial infarction; $P C I$, percutaneous coronary intervention; $C O P D$, chronic obstructive pulmonary disease; $I A B P$, intra-aortic balloon pump; $I R$, incomplete revascularization. 
TABLE E11. Double robust analysis on mortality within 30 days

\begin{tabular}{|c|c|c|c|}
\hline & Effect & Lower $95 \%$ CI & Upper $95 \%$ CI \\
\hline OPCAB & 1.4 & 0.75 & 2.61 \\
\hline Age & 1.05 & 1.005 & 1.09 \\
\hline Female & 1.64 & 0.86 & 3.14 \\
\hline BMI & 0.81 & 0.55 & 1.2 \\
\hline Canadian Cardiovascular Class & 1.65 & 0.81 & 3.36 \\
\hline NYHA class & 1.17 & 0.59 & 2.29 \\
\hline MI within $30 \mathrm{~d}$ & 1.01 & 0.48 & 2.13 \\
\hline PCI & 1.49 & 0.49 & 4.54 \\
\hline $\mathrm{DM}$ on insulin & 1.49 & 0.79 & 2.8 \\
\hline Current smoking & 0.24 & 0.03 & 1.78 \\
\hline Creatinine $>200 \mathrm{mmol} / \mathrm{L}$ & 1.03 & 0.23 & 4.54 \\
\hline COPD & 0.59 & 0.17 & 1.99 \\
\hline Cerebrovascular accident & 1.5 & 0.52 & 4.32 \\
\hline Peripheral vascular disease & 1.54 & 0.74 & 3.18 \\
\hline Atrial fibrillation & 2.16 & 0.83 & 5.66 \\
\hline 3-vessel disease & 1.39 & 0.62 & 3.14 \\
\hline Left main disease & 0.83 & 0.42 & 1.66 \\
\hline Left ventricular ejection fraction $30 \%-49 \%$ & 2.59 & 1.3 & 5.17 \\
\hline Left ventricular ejection fraction $<30 \%$ & 3.79 & 1.54 & 9.32 \\
\hline Cardiogenic shock & 1.24 & 0.06 & 25.92 \\
\hline Preoperative IABP & 0.54 & 0.03 & 10.61 \\
\hline Nonelective & 2.25 & 1.04 & 4.86 \\
\hline Emergency/salvage & 1.55 & 0.27 & 9 \\
\hline Era of surgery & 0.76 & 0.4 & 1.46 \\
\hline Bilateral internal thoracic arteries & 4.01 & 0.49 & 33.02 \\
\hline Radial artery & 0.35 & 0.08 & 1.51 \\
\hline IR & 0.79 & 0.3 & 2.11 \\
\hline
\end{tabular}

CI, Confidence interval; OPCAB, off-pump coronary artery bypass; BMI, body mass index; NYHA, New York Heart Association; $M I$, myocardial infarction; $P C I$, percutaneous coronary intervention; $D M$, diabetes mellitus; $C O P D$, chronic obstructive pulmonary disease; $I A B P$, intra-aortic balloon pump; $I R$, incomplete revascularization. 
TABLE E12. Double robust analysis on incomplete revascularization

\begin{tabular}{|c|c|c|c|}
\hline & Effect & Lower $95 \%$ CI & Upper $95 \%$ CI \\
\hline OPCAB & 2.41 & 1.75 & 3.32 \\
\hline Age & 1.17 & 0.92 & 1.49 \\
\hline Female & 1.4 & 1 & 1.96 \\
\hline BMI & 0.94 & 0.78 & 1.14 \\
\hline Canadian Cardiovascular Class & 0.87 & 0.63 & 1.2 \\
\hline NYHA class & 1.18 & 0.85 & 1.65 \\
\hline MI within $30 \mathrm{~d}$ & 0.79 & 0.53 & 1.19 \\
\hline PCI & 0.66 & 0.35 & 1.21 \\
\hline DM on insulin & 0.99 & 0.73 & 1.35 \\
\hline Current smoking & 0.87 & 0.52 & 1.46 \\
\hline Creatinine $>200 \mathrm{mmol} / \mathrm{L}$ & 1.07 & 0.52 & 2.17 \\
\hline COPD & 1.16 & 0.72 & 1.86 \\
\hline Cerebrovascular accident & 1.01 & 0.55 & 1.87 \\
\hline Peripheral vascular disease & 1.01 & 0.67 & 1.53 \\
\hline Atrial fibrillation & 0.95 & 0.48 & 1.91 \\
\hline 3-vessel disease & 1.21 & 0.86 & 1.71 \\
\hline Left main disease & 1.19 & 0.85 & 1.67 \\
\hline Left ventricular ejection fraction $30 \%-49 \%$ & 0.99 & 0.55 & 1.77 \\
\hline Left ventricular ejection fraction $<30 \%$ & 0.52 & 0.05 & 5.47 \\
\hline Cardiogenic shock & 1.14 & 0.35 & 3.68 \\
\hline Preoperative IABP & 1.18 & 0.84 & 1.64 \\
\hline Nonelective & 1.4 & 0.43 & 4.54 \\
\hline Emergency/salvage & 1.48 & 1.13 & 1.93 \\
\hline Era of surgery & 1.48 & 0.5 & 4.41 \\
\hline Bilateral internal thoracic arteries & 0.21 & 0.13 & 0.35 \\
\hline Radial artery & 0.56 & 0.33 & 0.91 \\
\hline
\end{tabular}

$C I$, Confidence interval; $O P C A B$, off-pump coronary artery bypass; $B M I$, body mass index; $N Y H A$, New York Heart Association; $M I$, myocardial infarction; $P C I$, percutaneous coronary intervention; $D M$, diabetes mellitus; $C O P D$, chronic obstructive pulmonary disease; $I A B P$, intra-aortic balloon pump; $I R$, incomplete revascularization. 
TABLE E13. Double robust analysis on late mortality

\begin{tabular}{|c|c|c|c|}
\hline & Effect & Lower $95 \%$ CI & Upper $95 \%$ CI \\
\hline OPCAB & 1.09 & 0.91 & 1.29 \\
\hline Age & 1.06 & 1.04 & 1.07 \\
\hline Female & 0.92 & 0.76 & 1.12 \\
\hline BMI & 1.13 & 1.01 & 1.27 \\
\hline Canadian Cardiovascular Class & 1.02 & 0.84 & 1.23 \\
\hline NYHA class & 1.06 & 0.87 & 1.28 \\
\hline MI within $30 \mathrm{~d}$ & 0.72 & 0.54 & 0.95 \\
\hline PCI & 1.02 & 0.66 & 1.59 \\
\hline DM on insulin & 1.18 & 1 & 1.4 \\
\hline Current smoking & 1.27 & 0.93 & 1.72 \\
\hline Creatinine $>200 \mathrm{mmol} / \mathrm{L}$ & 2.5 & 1.68 & 3.72 \\
\hline COPD & 1.38 & 1.03 & 1.83 \\
\hline Cerebrovascular accident & 1.8 & 1.34 & 2.42 \\
\hline Peripheral vascular disease & 1.72 & 1.39 & 2.14 \\
\hline Atrial fibrillation & 1.82 & 1.32 & 2.52 \\
\hline 3-vessel disease & 0.87 & 0.71 & 1.07 \\
\hline Left main disease & 1.1 & 0.9 & 1.35 \\
\hline Left ventricular ejection fraction $30 \%-49 \%$ & 1.31 & 1.08 & 1.59 \\
\hline Left ventricular ejection fraction $<30 \%$ & 2.28 & 1.71 & 3.03 \\
\hline Cardiogenic shock & 0.48 & 0.09 & 2.44 \\
\hline Preoperative IABP & 1.2 & 0.39 & 3.7 \\
\hline Nonelective & 1.18 & 0.97 & 1.42 \\
\hline Emergency/salvage & 1.13 & 0.53 & 2.41 \\
\hline Era of surgery & 0.91 & 0.66 & 1.23 \\
\hline Bilateral internal thoracic arteries & 0.87 & 0.43 & 1.77 \\
\hline Radial artery & 1.07 & 0.84 & 1.36 \\
\hline IR & 1.49 & 1.15 & 1.92 \\
\hline
\end{tabular}

CI, Confidence interval; $O P C A B$, off-pump coronary artery bypass; $B M I$, body mass index; $N Y H A$, New York Heart Association; $M I$, myocardial infarction; $P C I$, percutaneous coronary intervention; $D M$, diabetes mellitus; $C O P D$, chronic obstructive pulmonary disease; $I A B P$, intra-aortic balloon pump; $I R$, incomplete revascularization. 


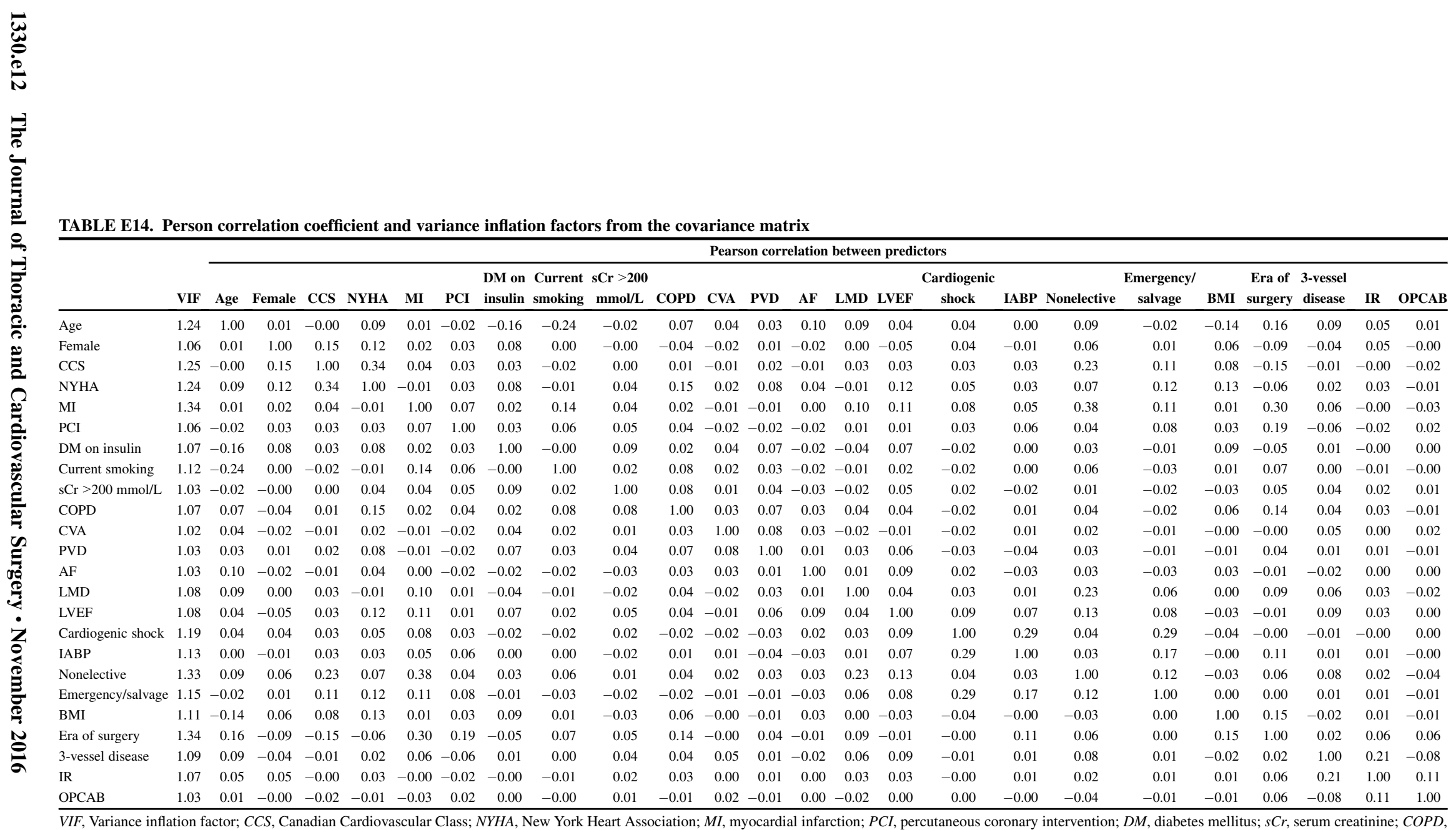

$V I F$, Variance inflation factor; $C C S$, Canadian Cardiovascular Class; $N Y H A$, New York Heart Association; $M I$, myocardial infarction; $P C I$, percutaneous coronary intervention; $D M$, diabetes mellitus; $s C r$, serum creatinine; COPD, body mass index; $I R$, incomplete revascularization; $O P C A B$, off-pump coronary artery bypass. 